\title{
FAMILIA COMO SUPORTE PARA A MULHER EM TRATAMENTO QUIMIOTERÁPICO
}

\author{
THE FAMILY AS A SUPPORT TO THE WOMAN IN CHEMOTHERAPIC TREATMENT
}

\author{
Raimunda Magalhães da Silva ${ }^{2}$ \\ Elizabeth Mesquita Melo² \\ Maria Socorro Pereira Rodrigues ${ }^{3}$
}

\begin{abstract}
RESUMO: Visa identificar a percepção da mulher mastectomizada acerca do apoio familiar, durante o tratamento quimioterápico; que tipo de enfrentamento adotam a mulher e a família, frente as dificuldades referentes ao tratamento quimioterápico e que mudanças são desencadeadas no convívio familiar. A coleta dos dados foi realizada com mulheres que realizam tratamento em uma instituição especializada, e ateve-se a critérios previamente estabelecidos, atendendo também os padrões burocráticos e éticos estabelecidos pela instituição. A amostra constou de 20 mulheres em faixa etária que variava entre 32 e 77 anos de idade.0s depoimentos, exceto um, foram colhidos por meio de gravador. Os resultados mostram que, no enfrentamento das situações decorrentes da quimioterapia, as mulheres costumam utilizar mecanismos que favoreçam a sua adaptação, conversando com amigos, saindo e se divertindo, ou ocupando o tempo para esquecer os problemas. A religião constitui, também, um fator importante na reabilitação da mulher. A força e desejo de ficar boa são armas importantes para vencer as dificuldades que o tratamento quimioterápico Ihes impõe. A ajuda que recebem da familia é em forma de apoio emocional, financeiramente e em afazeres domésticos.
\end{abstract}

PALAVRAS CHAVE: Família; Mulher; Quimioterapia; Enfermagem.

\section{INTRODUÇÃO}

Dentre os problemas de saúde pública que vêm a cada dia se proliferando, afetando tanto a população masculina como a feminina, estão os tumores malignos. Nas mulheres, os tipos mais comuns são o câncer de mama e do colo uterino, responsáveis pela morte de um elevado número de brasileiras entre todas as idades, predominando, porém, na faixa etária acima de 40 anos.

A incidência de câncer de mama no Brasil vem crescendo e, de acordo com a estatística destacada pelo INCA (1998), o câncer de mama classifica-se em primeiro lugar dos casos de neoplasia maligna. Foi estimado para o ano de 1998 o aparecimento de 32.695 casos e um total de 7.165 óbitos por essa patologia.

Nesse contexto, no momento em que a mulher descobre alguma alteração em sua mama, pode adiar a confirmação do diagnóstico em razão do medo relacionado aos tratamentos que poderão ser estabelecidos. Estes incluem a cirurgia, radioterapia, tratamento quimioterápico e hormonal, podendo haver associação entre estes.

0 tratamento comumente indicado é a mastectomia, que consiste na retirada da mama ou de parte desta. A tualmente procura-se ao máximo conservar esse órgão. A mastectomia total só é empregada quando o tumor já está num estágio muito avançado e a mastectomia parcial associada à quimiotera pia não resolvem. Logo, percebe-se a importância da detecção precoce do nódulo, a fim de um tratamento menos traumatizante e mais eficiente, possibilitando maiores chances de cura.

Braccio (1997) enfatiza a importância de o câncer ser diagnosticado em estágio inicial, para evitar a mastectomia. Atenção especial, entretanto, deve ser dada ao auto-exame mensal das mamas, à visita periódica ao ginecologista e à realização dos exames solicitados pelo médico. Isso, entretanto, nem sempre é seguido pelas mulheres, em razão de uma série de dificuldades, seja de ordem econômica ou psico-emocional.

\footnotetext{
Doutora em Enfermagem. Professora do Departamento de Enfermagem da Universidade Federal do Ceará

Enfermeira. Mestranda do Programa de Pós-Graduação em Enfermagem da Universidade Federal do Ceará

Professora Adjunta. Doutora do Departamento de Enfermagem da Universidade Federal do Ceará
} 
Quando o câncer se torna detectável clinicamente, poderá já se encontrar em estágio avançado, pois já sofreu pelo menos 30 duplicações, havendo uma grande oportunidade de estabelecer micrometástases à distância. Torna-se então necessário o controle da doença à distância, através da quimioterapia adjuvante (O liveira Filho, 1994).

A mulher portadora de carcinoma mamário, juntamente com o seus familiares, via de regra, antes de iniciar o tratamento, passa por conflitos psicológicos e distúrbios emocionais. Muitas vezes, até chegar à decisão de se tratar, esta percorre uma trajetória difícil, dolorosa e repleta de dúvidas. Isto deve-se ao fato de ser a mama um órgão ao qual, tanto as mulheres quanto à sociedade, atribuem grande importância. Decorrem daí, também, o medo da cirurgia e o conseqüente retardo do tratamento.

Em pesquisas realizadas no Brasil, foram percebidas as dificuldades apresentadas pelas mulheres portadoras de carcinoma mamário frente à necessidade de operar-se, e também, relacionadas aos outros tratamentos indicados, tais como a quimioterapia e a radioterapia. Essas dificuldades estão associadas aos efeitos colaterais conseqüentes dos tratamentos e das repercussões que os efeitos destes produzem no âmbito social e familiar dessa mulher. Reconhecendo então, que as dificuldades sofridas por mulheres acometidas pelo câncer são muitas e amplas, procuramos através deste estudo respostas para as seguintes questões:

1. Qual a percepção da mulher mastectomizada acerca do apoio familiar, durante o tratamento quimioterápico?

2. Qual o tipo de enfrentamento que têm a mulher e a família frente às dificuldades referentes ao tratamento quimioterápico?

3. Que mudanças ocorrem no convívio familiar?

Com o intuito de explorar tais questões, buscamos analisar o suporte familiar recebido pela mulher mastectomizada, no enfrentamento do tratamento quimioterápico, relacionando-o às mudanças ocorridas no convívio familiar.

Aspectos relacionados a quimioterapia e suporte familiar

A utilização dos agentes antineoplásicos tem o intuito de promover a morte das células tumorais, provocando sua interferência com as funções e a reprodução das células. Essas drogas são usadas, principalmente, para tratar mais a doença sistêmica do que as lesões localizadas, suscetíveis à cirurgia ou irradiação. A quimioterapia é, em geral, associada à cirurgia ou à radioterapia, ou a ambas, para reduzir 0 tamanho do tumor (S meltzer e Bare, 1994).

A quimioterapia como modalidade de tratamento do câncer de mama tem o seu papel estabelecido, seja em caráter neo-adjuvante, adjuvante ou paliativo. Enquanto não se conseguir reverter o processo biológico que altera o comportamento da célula maligna, a quimioterapia continuará sendo usada como método auxiliar na tentativa de cura ou de aumento de sobrevida, em pacientes portadoras de carcinoma mamário (Simon, 1994).

Em geral, é feita a combinação de dois ou mais agentes para a obtenção de uma resposta mais eficiente. Esta combinação tem a vantagem também de diminuir a incidência e a severidade dos efeitos colaterais, visto que um dos agentes serve para reverter o efeito indesejado do outro (Bender, 1997).

As combinações de drogas usadas no tratamento quimioterápico do câncer de mama, para Entrekin (1997), são, em geral, administradas por um período de 3 a 6 meses. A seguinte terapia é considerada padrão para este tipo de câncer: ciclofosfamida, metotrexate e 5-fluorouracil (CMF). Posteriormente, tem-se eletivamente: ciclofosfamida, doxorrubicina, 5-fluorouracil (CAF); CMF com vincristina e prednisona (CMFVP), e doxorrubicina e ciclofosfamida (AC).

As ações e efeitos colaterais das principais medicações antineoplásicas utilizadas no tratamento quimioterápico do câncer de mama, estão relacionados no quadro a seguir: 


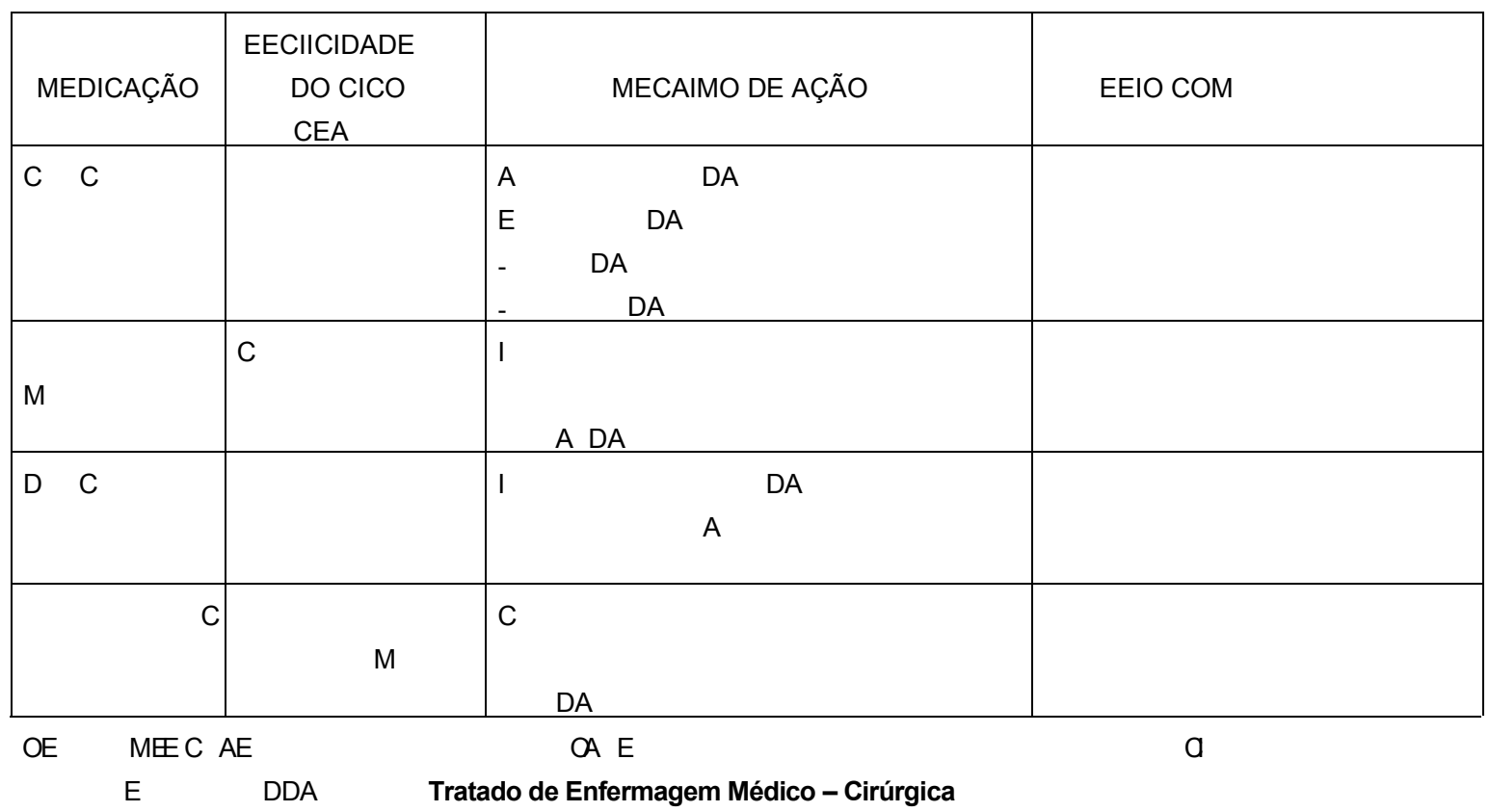

As drogas antineoplásicas, conforme Smeltzer e Bare (1994), podem ser administradas por via tópica, oral, intravenosa, intramuscular, subcutânea, arterial, intracavitária e intratecal. A escolha da via depende do tipo da medicação, da dose necessária, da localização e extensão do tumor a ser tratado.

Marreiro e Araújo (1998) afirmam que se pode considerar a quimioterapia um grande avanço na cura e controle do câncer, aumentando a expectativa de vida do cliente. É essencial, entretanto, que os profissionais de saúde que atuam junto a clientes oncológicos tornem efetivas as orientações referentes aos objetivos e efeitos colaterais do tratamento quimioterápico, além, sobretudo, de oferecer apoio emocional, de modo a elevar a auto-estima e incentivar o autocuidado desses clientes.

A família pode ser definida como um sistema social humano com características distintas, composta de indivíduos com características igualmente distintas. Reconhecidamente, representa um fator importante para 0 desenvolvimento e um suporte do indivíduo por ocasião de uma doença, (Friedemann, 1989). Durante 0 tratamento quimioterápico, o relacionamento das mulheres com seus familiares, muitas vezes, depende da percepção do seu corpo, ficando envolvidas a auto-imagem e a auto-estima. Tanto a mastectomia como a quimioterapia alteram a imagem corporal e 0 autoconceito, refletindo de forma negativa na identidade feminina. No convívio familiar, existem conflitos que poderão ser contornados, desde que todos aceitem e se adeqüem à nova situação de vida, imposta pela circunstância do tratamento. Lansberry (1992) refere que a família representa um fator de grande influência para o indivíduo, com as condições de oferecer suporte para sua adaptação e equilíbrio. No tratamento e na reabilitação da mulher mastectomizada, torna-se fundamental o apoio proporcionado pelos familiares, amigos ou outras pessoas que exerçam influências favoráveis sobre esta, uma vez que, após a intervenção cirúrgica, na maioria das vezes, são estabelecidos tratamentos agressivos podendo prolongar-se por um longo período.

A importância da participação efetiva da família é ressaltada por Silva (1998), referindo que poderá ser objetivada a partir do apoio emocional, da compreensão, de forma material e financeira, o que contribuirá positivamente na trajetória da mulher durante o tratamento.

\section{METODOLOGIA}

É um estudo de caráter descritivo, sobre o suporte familiar das mulheres mastectomizadas em tratamento quimioterápico. Realizado numa instituição especializada em Oncologia, especificamente no setor de quimioterapia, localizada na cidade de Fortaleza.

Antes de se iniciar a pesquisa, foram observados os trâmites burocráticos legais determinados pela instituição, onde se incluem a observação e o respeito aos aspectos éticos. Estabelecemos como critério que 
as mulheres incluídas no estudo deveriam ter realizado pelo menos uma aplicação de quimioterapia, e desde que a mesma concordasse em participar da pesquisa. Foram-lhes garantidos 0 anonimato, a liberdade de participação, o direito de interromper e omitir dados, além de assinatura de um termo de consentimento, garantindo sua inclusão na pesquisa. As mulheres foram identificadas no estudo, através de nomes fictícios, simbolizados por pedras preciosas. As entrevistas foram realizadas num clima de empatia, tendo, à medida do possível, sido oferecido o conforto físico e emocional necessário.

0 contingente amostral foi definido a partir da saturação dos depoimentos, considerando o fato de que os mesmos atendiam as expectativas do estudo, que correspondeu a 20 mulheres mastectomizadas, entrevistadas no período de 4 a 22 de janeiro de 1999, em dias alternados e nos turnos da manhã e da tarde.

Os dados foram coletados através de entrevista semi-estruturada, realizadas durante a aplicação do quimioterápico, com duração média de 50 minutos, incluindo os dados de identificação. Foi um momento considerado agradável pelas mulheres, por ter o mesmo propiciado o diálogo, por ela ter sido ouvida, ter expressado seus sentimentos. Os depoimentos, com exceção de um, foram gravados, conforme 0 consentimento das participantes.

Os dados foram organizados e agrupados em categorias, contendo as falas mais significativas e que melhor se adequavam aos objetivos propostos.

A análise teve a finalidade de estabelecer uma compreensão dos dados coletados, confirmar ou não os pressupostos do estudo, subsidiando as questões formuladas. Visou também a ampliar o conhecimento relativo ao assunto abordado, articulando-o ao contexto cultural do qual faz parte (Minayo, 1994).

\section{APRESENTAÇÃO E ANÁLISE DOS RESULTADOS}

As mulheres participantes do estudo estavam na faixa etária de 32 a 77 anos, sendo que a maioria se encontrava acima de 45 anos, eram casadas e procedentes da cidade de Fortaleza. 0 grau de instrução variou entre analfabetas (08); 1으 grau incompleto (8); 2ำ grau completo (03) e nível superior (01). Quanto à ocupação, as mulheres em sua maioria eram donas de casa. Vale ressaltar que, entre todas as mulheres, apenas uma continuava exercendo sua profissão, pois as demais estavam aposentadas ou afastadas. No que se refere à renda familiar, 13 participantes tinham renda inferior a dois salários.

Para melhor compreensão, os resultados foram analisados de acordo com a percepção da mulher frente às conseqüências da quimioterapia, o apoio dos familiares e as mudanças ocorridas no convívio familiar.

\section{A conseqüência da quimioterapia e o apoio familiar}

A percepção das mulheres sobre a quimioterapia volta-se, quase sempre, às conseqüências desagradáveis referentes à sintomatologia, dificuldades para suportar os problemas adversos e decorrentes do tratamento.

A maioria das mulheres do estudo já estava em tratamento há algum tempo. Muitas delas voltaram por conta de metástases. Logo, já haviam tido um contato com a quimioterapia, sem falar que uma grande parte havia realizado o tratamento pré-cirurgia, para redução do tumor. Esse contato anterior com a quimioterapia contribui para uma melhor aceitação e menor apresentação de efeitos colaterais. 0 início do primeiro tratamento com drogas antineoplásicas costuma causar mais impacto à mulher do que os tratamentos subseqüentes. Isto está refletido nas seguintes falas:

“Na primeira, eu me senti muito mal. Passava três dias sem comer, sem beber, até água. Provocando direto. Essas drogas até que tem maneirado mais. Melhorou cem por cento. As primeiras foram horrível. A família quando tem dinheiro ajuda. É, essa que veio aqui mais eu, ia duas vezes por semana na minha casa. Mas ela mora longe. Quando chegar o invero, ela nem vai poder mais vim. Tem dois meninos" (Turmalina).

"A primeira vacina, eu quase morro. Passei o mês só provocando, não comia nada... Agora quando foi a outra, eu não senti não... minhas duas filhas são muito boas pra mim. Eu tinha quatro, morreram duas, ficaram duas. Deus é muito bom pra mim, sabia que eu ia precisar dessas duas meninas. Elas fazem tudo. Meu marido é muito bom. Sempre foi. Desde que casamos. Não tenho do que me queixar" (Rubi). 
"No início eu achei que Deus tinha me abandonado, assim porque eu tava num tratamento desses. Porque eu nunca pensei.A minha família diz que gosta muito de mim. Tem irmã minha que nunca ligou pra mim, pra conversar comigo. Eu acho que ela não quer que eu sinta que ela tá com pena de mim, ou tá preocupada, sabe? Eu entendo isso aí delas. Mas a minha mãe me ajudou também. Ela disse que eu ia ficar boa. Sempre ela liga pra mim. Sempre eu vejo ela. Ela disse que eu faça o tratamento que eu vou ficar boa" (J ade).

A família representa um ponto de apoio importante para as mulheres mastectomizadas, tanto no que se refere ao apoio emocional como à ajuda nos afazeres domésticos, manifestação de carinho e ajuda financeira.

Silva e Mamede (1998) evidenciaram a importância da família como apoio, para a mulher mastectomizada enfrentar situações advindas de sua nova condição. Assim, esta procura organizar seus relacionamentos sociais, constituídos por uma rede de elementos que envolve pessoas da família, amigos, profissionais de saúde e outros grupos que poderão ajudá-la durante a reabilitação.

A notícia de que vai ter que reiniciar o tratamento é capaz de produzir na mulher conflitos psicológicos, que poderão ocasionar fortes efeitos colaterais.

"Tive uma depressão muito grande quando soube que ia ter que fazer novamente quimioterapia. Fiquei na fossa. Quando chego para fazer a quimio, chego num estado deplorável. Minha família não ajuda em nada. Eles ficam tão nervosos que fazem barulho, tudo o que eu não gosto. Choram, ficam tristes. Meu irmão é um idiota. Quando cheguei contando que a doença tinha voltado, que estava com provável mestástase no pulmão, ele mandou eu parar de falar. Sabe por quê? Porque ele estava comendo, e tinha nojo" (Esmeralda).

"Bem, agora... pra retornar, eu senti muita tristeza. Ontem à noite eu nem dormi, pensando: pô, vou voltar de novo, sabe? Acho que dou mais forças pra família. Eu noto que eles olham pra mim com tristeza. Se for assim vai morrer antes do tempo, porque eu vou viver muito" (Ágata).

"Sim. Agora me sinto mais deprimida do que da primeira vez. Agora, eu sinto demais. Da primeira vez eu não sentia não, trabalhava normal. Saía, dançava... A minha irmã me ajuda muito. Ela que comprou minha peruca. Ela faz tudo. Compra minha medicação. Tudo que eu preciso é com ela. Só basta eu dizer que tô sentindo qualquer coisa. Ela é uma mãe pra mim" (Opala).

Às vezes a família fica tão abalada com a doença e com os tratamentos, que sofre um desequilíbrio e não tem capacidade de oferecer o apoio de que a mulher tanto necessita. Isto pode acarretar um prejuízo na recuperação da mulher.

A inadequação dos elementos de suporte social, representados pela família, amigos e pessoas da convivência da mulher, poderá dificultar o seu ajustamento social, especialmente se ela já tiver dificuldades para enfrentar as situações difíceis do cotidiano (Rodrigues et al., 1998).

De acordo com Simonton (1990), não é fácil aceitar um diagnóstico de câncer, não importa os conhecimentos que se tenha sobre a doença. Nesta árdua luta contra o diagnóstico de câncer, o impacto do medo do desconhecido atinge não somente o paciente, porquanto todos da família ficam naturalmente tão perturbados que não conseguem viver normalmente.

Segundo Fernandes (1997), o diagnóstico de câncer leva a um momento de crise, tanto para a pessoa afetada como para sua família e o ambiente social no qual ela está inserida.

Foram expressados sentimentos de tristeza, medo, raiva e revolta ante à realização do tratamento quimioterápico, muitas vezes relacionados aos sintomas, especialmente à queda de cabelo. Mas, ao mesmo tempo, justificam a continuidade do tratamento pela vontade de obterem a cura. Vejamos o exposto nos seguintes depoimentos:

"Quando tá perto do dia, eu já fico nervosa, eu não gosto de vim pra cá. Tenho medo. Minha mãe me ajuda. Não em casa. Me dá força" (Pérola).

"Eu acho que essas vacinas não tem quem goste. A gente só faz, porque a gente quer a saúde. Minha família não ajuda. Os dois filhos moram distante. E minha filha é casada" (Granada).

“Dá muita angústia. Dá muita tristeza (choro). É, a gente fica com aquele mal estar. Mas eu luto. Não me entrego. Eu fico esmorecida, tenho muito suor frio...com aquela agonia. Minha família tem muito cuidado comigo. Uma cuida, outra cuida. Minha filha não me deixa só. Meu filho não me deixa só. Todo mundo é amigo. Até as empregadas das minhas irmãs tem muito cuidado comigo. Meus sobrinhos também" (Amazonita). 
A ansiedade e o medo estão quase sempre presentes em pacientes submetidos a quimioterapia. 0 medo está relacionado aos efeitos colaterais que o tratamento costuma causar, mas freqüentemente não impede o prosseguimento com o tratamento.

Para Pérola e Amazonita, o apoio da família representa mais um indicador que fortalece a continuidade do tratamento, enquanto, para Granada, a insuficiência, a ausência do apoio dos filhos poderá repercutir de forma insatisfatória na readaptação e no equilíbrio do processo saúde-doença.

As respostas das mulheres foram, de uma maneira geral, ineficazes e são refletidas em medo, depressão, angústia e tristeza. Até certo ponto, essas respostas podem estar associadas ao pouco esclarecimento com relação ao tratamento quimioterápico e também à própria doença. Nesse contexto, a enfermagem poderia priorizar essa deficiência de conhecimentos, realizando atividades mais efetivas de orientação, como também intensificar 0 apoio no plano psicológico, a fim de minimizar os conflitos emocionais.

0 tratamento quimioterápico apresenta muitas dificuldades e especificamente as relacionadas aos efeitos colaterais, à tristeza, deslocamento para a instituição, à situação financeira, entre outros.

“E njôo. E um negócio que dá no corpo da gente, e na boca. Tenho muito apoio deles. Apesar de não ser minha família" (Titanita)

“É ...acho ruim...sabe o que é, o tratamento, uma dificuldade que eu acho...minha situação financeira. A família me ajuda bastante a levantar 0 astral. E quando podem me ajuda financeiramente" (Ametista).

“Ave Maria, eu acho difícil porque a viagem, é longe. Minha filha me ajuda, mas está operada aqui também” (Rodonita).

“[...] o mais difícil que eu tô achando, só porque a gente não tem dinheiro. Toda vida quando a gente é pra vim, é o maior sacrifício, pra arrumar um tostãozinho. Não me ajudam, porque não podem. Minha nora me dá uma ajuda, mas tem quatro filhos, mesmo assim me dá uma mãozinha.. Mas ela adoeceu da coluna, aí ficou mais difícil" (Turquesa).

Outros fatores citados como dificuldades impostas pelo tratamento relacionam-se ao fato de ter que deixar a família sozinha em casa e a demora para receber 0 atendimento.

"Deixar minha filha lá. Minha filha. Eu queria trazer minha filha (choro). Meus filhos ajudam. Eu não faço nada. E agora principalmente. Minha filha de oito anos, dá banho em mim, me enxuga" (Safira).

"O mais difícil que eu acho mesmo é quando a gente vem, que a gente demora muito. Porque eu cheguei aqui uma da tarde, né? E agora que eu tô aqui. A família me dá a maior força. Meu esposo me ajuda. Tá todo mundo feliz porque estou bem" (O bsidiana).

No cotidiano dessas mulheres há fatores que interferem de forma satisfatória ou insatisfatória na sua adaptação ao tratamento. Entre estes, destacamos as dificuldades financeiras, a ausência da família, a solidão, os conceitos pessoais associados à vida e à morte, a dificuldade com transporte e a espera pelo atendimento no serviço de saúde.

A quimioterapia é um tratamento baseado na aplicação de uma ou mais drogas antineoplásicas, com o objetivo de cura, controle ou ação paliativa sobre o câncer. 0 câncer normalmente ocasiona alguns efeitos no plano local ou sistêmico, tais como: anorexia, vômitos, náuseas, estomatite, alopecia e alterações referentes ao humor, entre os mais freqüentes. Vale salientar que os efeitos colaterais são peculiares a cada droga, e podem, ainda, variar de pessoa para pessoa.

Quanto aos principais problemas relativos à quimioterapia, as mulheres revelaram que os efeitos colaterais representavam um dos maiores problemas, medo das reações das pessoas e medo da doença.

As dúvidas e interrogações são freqüentes durante o tratamento quimioterápico; a procura de esclarecimentos sobre a doença é comum, porém, a mulher tem medo de mencionar a palavra câncer, mesmo sabendo da doença (Marreiro \& Araújo, 1998).

Foi encontrada, ainda, uma pequena parte das mulheres que revelaram não perceber nenhum problema relacionado ao tratamento. Elas justificaram que, apesar de esporadicamente sentirem alguns efeitos, tentam contornar a situação porque sabem que o tratamento irá ajudá-las na cura, ou então, tentam ser mais fortes do que as drogas.

Algumas mulheres mastectomizadas passam por momentos difíceis, desde o diagnóstico de câncer, continuando no tratamento. Esta sofre no momento do diagnóstico; o medo invade sua mente e surge a pergunta 
inevitável: será que vou morrer? Isto porque o câncer está, quase sempre, associado à morte, à doença sem cura, a o fim.

Após essa fase, ao ser cientificada de que terá que realizar uma cirurgia, a mastectomia, a mulher enfrenta outra situação difícil - a amputação de um órgão que, para ela, é essencial na definição de seu gênero, faz parte do "ser mulher". Então, a mesma vive momentos de conflitos psicológicos, afetando a sua imagem corporal e a auto-estima.

Nesse sentido, quando essa mulher, que já vivenciou tudo isso, ainda tem que enfrentar um tratamento agressivo, como a quimioterapia, não é de se admirar que surja a dúvida: será que vale a pena continuar lutando? Todavia, ainda assim, de praxe, observa- se que, não se sabe de onde, essa mulher encontra forças para levar o tratamento adiante, pois acredita na vida.

As mulheres expressaram que, em algum momento do tratamento, já haviam pensado em parar. Pensaram até mesmo em desistir da cirurgia.

No que concerne ao tratamento quimioterápico, consideráveis relatos demonstram a ocorrência da dúvida em continuà-lo, seja por conta dos efeitos colaterais ou por causa da situação financeira.

As relações de interdependência são fundamentais para estimular a mulher a continuar o tratamento. A interação social com pessoas que a mulher considera significativas pode ocasionar respostas positivas relacionadas aos sentimentos de amor, afeição, valorização e respeito, presentes nas relações.

\section{Mudanças no convívio familiar}

As participantes do estudo deixaram transparecer em seus depoimentos que ocorreram mudanças no dia-a-dia, as quais afetaram o comportamento habitual. Foi destacado pelas mulheres, principalmente, o fato de terem parado de trabalhar, seja fora de casa ou realizando os afazeres domésticos no próprio lar.

"O que mudou foi que...parei de trabalhar. Eu gostava de fazer as minhas coisas, né?" (Turmalina).

"Mudou em tudo. O lha, eu trabalhava dois expedientes. Cuidava da minha casa, que eu sou...eu gosto muito de casa arrumada" (Amazonita).

"Desde quando eu soube assim....a minha vida ficou muito diferente. Mudou muito. Muito mesmo...Toda vida gostei muito de fazer minhas coisas. Aí não pude mais fazer" (J ade).

Na sociedade atual, após a emancipação da mulher, esta gosta de se sentir útil. Logo, é comum as mulheres trabalharem fora, para sentirem prazer, realizarem-se profissionalmente ou mesmo para contribuírem com as despesas da casa.

Nas mulheres entrevistadas ocorreram mudanças nos papéis por elas exercidos, exigindo uma resposta destas. As mulheres revelaram tristeza associada ao fato de terem interrompido suas atividades profissionais ou domésticas.

"Mudou. Eu não sou mais aquela que eu era antigamente. Fiquei mais deprimida. Eu era de...trabalhar. Muito trabalhadeira. 0 que me derrubou muito...foi eu não poder mais trabalhar" (Âmbar).

"Mudou porque eu parei de trabalhar...porque quando eu trabalhava, as minhas coisas era outra, né? Não faltava nada na minha casa e eu nunca pedi nada a ninguém. A gente não pode fazer as coisas da gente...toda coisa que a gente quer é obrigado pedir o povo" (Turquesa).

“Trabalhar...Eu acho ruim demais ter parado. Eu tô é doente porque não tô trabalhando. Foi ruim. Porque eu ganhava meu dinheirinho mais" (S afira).

As mudanças nos papéis foram enfrentadas e respondidas de forma ineficaz, evidenciadas por depressão e sentimento de dependência.

A recuperação e reabilitação da mastectomia são freqüentemente processos desgastantes, que podem ser acompanhados de limitações que as impossibilitam de desenvolver algumas atividades que costumeiramente realizavam (Rodrigues et al, 1998).

Outros relatos de mudanças no cotidiano, após a descoberta do nódulo, dizem respeito à imagem corporal e fator emocional. 
"Mudou só o corpo, porque também é diferente" (Granada)

"Fiquei mais triste" (Rubi).

"Mudou. Mudou tudo. Em relação assim às pessoas, minhas amizades. Eu tinha um namorado, depois que ele soube, ele não quis mais. Gostava de dançar, de beber, aquela coisa. Por ora eu não tenho mais vontade" (Opala).

Tais depoimentos mostram que as mudanças envolveram o autoconceito, uma vez que a visão da mulher acerca de si ficou alterada. A partir do momento em que ela percebe que as pessoas a enxergam de uma maneira diferente, ocorrerá mudanças no auto-conceito e, conseqüentemente, na auto-estima, vis to que 0 autoconceito constitui um pré-requisito para a auto-estima.

A mastectomia causa uma alteração na auto-estima da mulher e a quimioterapia potencializa essa alteração, já que ocasiona efeitos colaterais que afetam a mulher fisica e psicologicamente, implicando o autoconceito e auto-imagem.

A despeito do que foi exposto, algumas mulheres atribuíram à doença uma mudança positiva em suas vidas. Apesar de ser fato raro, estas declararam que, após o surgimento da doença, ocorreram alterações de cunho positivo no seu cotidiano.

"Mudou. Fiquei mais alegre, porque eu passei quatro anos doente, sofrendo" (Marcassita).

“Mudou só um pouco. Meu marido melhorou agora. Deixou de beber. Ele bebia. Agora não bebe mais não" (Cornalina).

"É...eu acho que mudou, né? Mudou assim, deu num querer mais saber de vaidade, nem de...de nada, né? Fiquei dando mais valor à vida" (Obsidiana).

Estas falas representam respostas adaptativas à situação. Percebemos que algumas mulheres encararam a doença como uma fator contribuinte para a melhora do seu cotidiano, ou seja, após a doença sua vida melhorou em algum aspecto.

\section{CONSIDERAÇÕES FINAIS}

Diante do exposto, observa-se que a mulher mastectomizada, quando na realização do tratamento quimioterápico, tende a ficar mais sensível e mais vulnerável às mudanças que ocorrem no seu cotidiano como conseqüência da doença.

A mudança mais observada entre as mulheres do estudo refere-se ao fato de elas terem interrompido suas atividades profissionais ou domésticas, visto que a maioria teve que parar de trabalhar ou realizar atividades relacionadas à cirurgia ou ao tratamento quimioterápico, havendo ocorrido também mudanças de hábitos, alterações emocionais e na imagem corporal.

Existem diversos estímulos que interferem na continuidade do tratamento quimioterápico. Entre os mais presentes, estão o medo relacionado aos efeitos colaterais, a situação financeira, a distância casa/instituição e a falta de conhecimento acerca do tratamento.

No enfrentamento das situações decorrentes da quimioterapia, as mulheres costumam utilizar mecanismos que favoreçam a sua adaptação. Nesse contexto, elas costumam conversar com os amigos, sair e se divertir ou ocupar o tempo para esquecer os problemas.

A família constitui um suporte importante na reabilitação da mulher à sua nova condição. De acordo com os relatos, os familiares ajudam tanto financeiramente quanto nos afazeres domésticos e oferecendo apoio emocional.

Apesar das dificuldades que o tratamento quimioterápico impõe às mulheres, estas demonstraram força e desejo de ficar boa. Houve momentos em que pensaram desistir da quimioterapia, porém não desistiram. Isso em razão de acreditarem no tratamento e em decorrência da fé que atribuem à religião.

Deixamos como sugestão um acompanhamento mais intensivo por parte das instituições e dos profissionais de saúde à mulher mastectomizada, em tratamento quimioterápico, no sentido de minimizar os problemas decorrentes do tratamento e contribuir para uma melhor qualidade de vida. 
ABSTRACT: The study aims to identify the mastectomized woman's perception about the family protection during the chemotherapy treatment and what changes are unchained in her familiar life. The data collection were achieved with women in treatment in a specialized institution and used a críterion previously established.The sample consisted of twenty women ranging from 32 to 77 years of age.The testimonies, except one, were taken through a record player. The results showed that when facing the situations after the chemotherapy the women used to get favourable mechanisms to their adaptation, such as, talking to friends, going out to entertainments and amusing themselves to occupy their in order to forget the problems. The religion also, has an important role in the woman's rehabilitation. Her strenght and will for recuperation are important feelings to overcome the difficulties imposed by the chemotherapy. The emotional and economical support and the household tasks were given as great help to those women by their relatives.

KEY WORDS: Family; Women; Chemotherapy.

\section{REFERÊNCIAS BIBLIOGRÁFICAS}

1. BENDER, C. Implicações da quimioterapia para a enfermagem. In: CLARK, J . C.; MACGEE, R. F. Enfermagem oncológica: um currículo básico. Porto Alegre: Artes Médicas, 1997. p.325-335.

2. BRACCIO, S. Reconstrução da mama: voltar a sentir. Cláudia, São Paulo, v.36, p.142-143, abr. 1997.

3. BRASIL. MINISTÉRIO DA SAÚDE. Secretaria Nacional de Assistência à Saúde. Instituto Nacional de Câncer - Pro - Onco. Estimativa da incidência e mortalidade por câncer no Brasil 1998. Pro - Onco, INCA, 1998.

4. ENTREKIN, N. Câncer de mama. In: CLARK, J . C.; MACGEE, R. F. Enfermagem oncológica. Porto Alegre : Artes Médicas, 1997. p.401-415.

5. FRIEDEMANN, M. L. The concept of family nursing. J . Adv. Nurs., Oxford, v.14, p.211-216, 1989.

6. FER NANDES,A. F. C. O cotidiano da mulher com câncer de mama. Fortaleza : Pós- Graduação, DENF, UFC Fundação Cearense de Pesquisa e Cultura, 1997. 96p.

7. LANSBERRY, C.R. Family nursing practice paradigm perspectives and diagnostic approaches. Adv Nurs Sci, v.15, n.2, p.66-75, 1992.

8. MARREIRO, C. L.; ARAÚJ O, T. L. Experiências de mulheres mastectomizadas que se submetem à quimioterapia. Fortaleza, 1998. Monografia (Especialização), Universidade Federal do Ceará.

9. MINAYO, M. C. S. Pesquisa Social: teoria, método e criatividade. 3. ed. Rio de J aneiro : Vozes, 1994.

10. OLIVEIRA FILHO, J . A. Quimioterapia adjuvante no câncer de mama. In: FARIA, S. L.; LEME, L. H. S.; OLIVEIRA FILHO, J. A. Câncer da mama: diagnóstico e tratamento. Rio de J aneiro : MEDSI, 1994. p.141-149.

11. RODRIGUES, D. P.; MELO, E. M.; SILVA, R. M.; MAMEDE, M. V. O suporte social para atender as necessidades de mulheres mastectomizadas. Rev. Bras. Cancerol., Rio de J aneiro, v.44, n.3, p.231-236, 1988.

12. SILVA, R. M. Mulher mastectomizada e o relacionamento familiar. In: VARELA, Z. M. V.; SILVA, R M.; BARROSO, M. G. T. Dimensões do cotidiano: violência doméstica, saúde da mulher e desempenho no trabalho. Fortaleza : PósGraduação, DENF/UFC, 1998. p.63-74.

13. SIMON, S. D. Câncer da Mama: Perspectivas futuras do tratamento quimioterápico. In: FARIA, S. L.; LEME, L. H. S.; OLIVEIRA FILHO, J . A. Câncer da mama: diagnóstico e tratamento. Rio de J aneiro : MEDSI, 1994. p. 253-257.

14. SIMONTON, S. M. A família e a cura. São Paulo : Summus, 1990. p.13-50.

15. SMELTZER, S. C.; BARE, B. G. Oncologia: A enfermagem e o paciente com câncer. In:____ BRUNNER/SUDDARTH. Tratado de Enfermagem Médico - Cirúrgica. Rio de J aneiro : Guanabara Koogan, 1994. v.1, p.291-330. 
